\title{
BMJ Open Controlled ovarian hyperstimulation for poor ovarian responders undergoing in vitro fertilisation/intracytoplasmic sperm injection: a protocol for systematic review and Bayesian network meta-analysis
}

\author{
Huisheng Yang (D) , ${ }^{1}$ Chensi Zheng, ${ }^{1,2}$ Qiyan Zheng (D) , ${ }^{3}$ Huanfang Xu, ${ }^{1}$ \\ Xiaotong Li, ${ }^{4}$ Mingzhao Hao (D) , ' Yigong Fang ${ }^{1}$
}

To cite: Yang $\mathrm{H}$, Zheng $\mathrm{C}$, Zheng Q, et al. Controlled ovarian hyperstimulation for poor ovarian responders undergoing in vitro fertilisation/intracytoplasmic sperm injection: a protocol for systematic review and Bayesian network meta-analysis. BMJ Open 2021;11:e039122. doi:10.1136/ bmjopen-2020-039122

- Prepublication history and additional material for this paper is available online. To view these files, please visit the journal online (http://dx.doi.org/10. 1136/bmjopen-2020-039122).

Received 04 April 2020 Revised 02 December 2020 Accepted 19 December 2020

Check for updates

(c) Author(s) (or their employer(s)) 2021. Re-use permitted under CC BY-NC. No commercial re-use. See rights and permissions. Published by BMJ.

For numbered affiliations see end of article.

Correspondence to Professor Yigong Fang; fangyigong@163.com

\section{ABSTRACT}

Introduction Controlled ovarian hyperstimulation $(\mathrm{COH})$ is the routine regimen used to generate a sufficient number of follicles during in vitro fertilisation (IVF) or intracytoplasmic sperm injection (ICSI) treatment. Poor ovarian response is a challenge encountered by many clinicians during $\mathrm{COH}$ and poor ovarian responders (PORs) usually have higher follicle stimulating hormone levels, lower levels of anti-Mullerian hormone and few oocytes retrieved, which have been attributed mainly to advanced maternal age and poor follicle reserve or other reasons that could impair ovarian response during ovarian stimulation. Over the last few decades, researchers have proposed a series of strategies and ovarian stimulation protocols to improve pregnancy outcomes in patients with POR during their IVF/ICSI treatment. However, clinical decisions regarding $\mathrm{COH}$ protocols in PORs during IVF/ICSI treatment remain controversial. Traditional pairwise metaanalysis only allows the direct comparison of two protocols in $\mathrm{COH}$ for patients with POR. However, many of these $\mathrm{COH}$ protocols have not been compared directly in randomised controlled trials (RCTs). Thus, we aim to use network meta-analysis (NMA) to assess the clinical effectiveness and safety of $\mathrm{COH}$ protocols and to generate treatment rankings of these $\mathrm{COH}$ protocols for the most clinically important and commonly reported outcomes events. Methods and analysis The PubMed, Embase, Cochrane Library, Web of Science, SinoMed, CNKI, WanFang database and Chongqing VIP information databases will be searched for all RCTs of $\mathrm{COH}$ for POR women during IVF/ ICSI from inception to 31 March 2020. Primary outcomes will include live birth rate and number of oocytes retrieved. Secondary outcomes will include ongoing pregnancy rate, clinical pregnancy rate, miscarriage rate, ovarian hyperstimulation syndrome rate, multiple pregnancy rate and cycle cancellation rate. Pairwise meta-analysis and Bayesian NMA will be conducted for each outcome. Subgroup analysis, meta-regression, and sensitivity analysis will be performed to assess the robustness of the findings. The generation of NMA plots and subsequent results will be performed by using R V.4.0.1. The
Strengths and limitations of this study

- Bayesian network meta-analysis (NMA) can integrate direct evidence with indirect evidence from currently applied controlled ovarian hyperstimulation protocols involving poor ovarian responder (POR) women undergoing in vitro fertilisation or intracytoplasmic sperm injection to generate a clinically useful ranking of these regimens.

- Only randomised controlled trials will be included.

- Evidence drawn from an NMA is limited and should be interpreted with caution.

- Different POR diagnostic criteria and various gonadotropin preparations may result in potential heterogeneity.

- The evidence of indirect comparison should be applied cautiously and reasonably in clinical practice.

assessment of confidence in network estimates will use the Confidence in Network Meta-Analysis)web application (see https://cinema.ispm.unibe.ch/).

Ethics and dissemination This review does not require ethics approval and the results of the NMA will be submitted to a peer-review journal.

In the 60 plus years between 1950 and 2017, the global total fertility rate has decreased by an estimated $49.4 \%{ }^{1}$ As such, infertility may have become a global problem. Moreover, the absolute number of couples affected by infertility increased from 42.0 million in 1990 to 48.5 million in $2010 .^{2}$ In vitro fertilisation and embryo transfer (IVF-ET) and intracytoplasmic sperm injection (ICSI) are wellestablished infertility treatments. However, only 23.44\% (90 618/386 632) of embryo transfers in in vitro fertilisation (IVF) or ICSI led to delivery based on data from 38 
countries and 1169 clinics in Europe. ${ }^{3}$ Furthermore, the cumulative live birth rate (LBR) among more than 3000 women who were poor ovarian responders (PORs) diagnosed according to the Bologna criteria ${ }^{4}$ was $14.9 \%(95 \%$ CI $13.7 \%$ to $16.1 \%) .{ }^{5}$ Generally, for IVF to be successful, adequate follicular recruitment and maturation are essential. POR is defined as the failure to develop a sufficient number of follicles after controlled ovarian hyperstimulation $(\mathrm{COH})$ in women undergoing assisted reproductive technology treatment. ${ }^{6}$ The incidence of POR varies worldwide and has been reported to range from $5.6 \%$ to $35.1 \%{ }^{7}$

$\mathrm{COH}$ is a routine regimen used to generate a sufficient number of follicles during IVF/ICSI treatment. ${ }^{8} \mathrm{COH}$ consists of three basic elements: exogenous gonadotropin (Gn) to stimulate multi follicular development; cotreatment with a Gn-releasing hormone $(\mathrm{GnRH})$ agonist or antagonist to suppress pituitary function and prevent premature ovulation; and triggering of final oocyte maturation 36 hours-38 hours before oocyte retrieval. Complex endocrine changes occur while a woman undergoes ovarian stimulation as part of IVF/ICSI treatment. The primary aims of $\mathrm{COH}$ are to create a cohort of developing follicles and to prevent premature spontaneous ovulation. ${ }^{9}$

Poor ovarian response is a challenge encountered by many clinicians during $\mathrm{COH}$, and PORs usually exhibit higher FSH levels, lower levels of anti-Mullerian hormone $(\mathrm{AMH})$ and few oocytes retrieved, which are attributed to advanced maternal age and/or poor follicle reserve or other reasons that could impair the ovarian response during ovarian stimulation. ${ }^{10}{ }^{11}$ Therefore, PORs usually undergo multiple repeated cycles, incur high costs and experience IVF failure. ${ }^{12}$ Various $\mathrm{COH}$ regimens and interventions have been proposed to improve pregnancy outcomes for patients with POR. Currently, the most frequently proposed $\mathrm{COH}$ protocols include delayed start GnRH antagonist protocol, ${ }^{14}$ short GnRH agonist protocol, ${ }^{15}$ mild ovarian stimulation protocol, ${ }^{16} \mathrm{GnRH}$ antagonist protocol, ${ }^{17}$ natural cycle protocol, ${ }^{18}$ long GnRH agonist protocol, ${ }^{19}$ stop GnRH agonist protocol, ${ }^{20}$ flare up GnRH agonist protocol, ${ }^{21}$ luteal phase ovarian stimulation protocol ${ }^{22}$ and progestin-primed ovarian stimulation protocol. ${ }^{23}$

Over the last few decades, researchers have proposed a series of strategies and ovarian stimulation protocols to improve pregnancy outcomes in patients with POR during their IVF/ICSI treatment. However, clinical decisions regarding $\mathrm{COH}$ protocols in PORs during IVF/ ICSI treatment remain controversial. Traditional pairwise meta-analysis only allows the direct comparison of two protocols in $\mathrm{COH}$ for patients with POR. ${ }^{24-37}$ However, many of these $\mathrm{COH}$ protocols have not been compared in randomised controlled trials (RCTs). Without direct evidence, it is difficult to identify the most effective $\mathrm{COH}$ protocol for patients with POR. As a useful tool that can rank the effectiveness of various treatments and subsequent guidance for clinical decision making, network meta-analysis (NMA) compares multiple various treatments in one statistical model. ${ }^{38}{ }^{39}$ The combination of direct and indirect evidence may improve the precision of the estimated effect sizes. ${ }^{40}$ The major value of NMA is that it can rank each $\mathrm{COH}$ protocol according to its effectiveness, which is important for clinicians to make the best treatment choices. NMA can additionally be used to identify gaps in the evidence base for designing future trial(s) and may reduce uncertainty in treatment-effect estimates. Therefore, we aim to use NMA to assess the clinical effectiveness and safety of current $\mathrm{COH}$ protocols and to generate treatment rankings of these $\mathrm{COH}$ protocols for the most clinically important and commonly reported outcome events.

\section{METHODS \\ Design}

This study will be based on a Bayesian framework for NMA, and will be performed according to the Preferred Reporting Items for Systematic Review and Meta-Analysis Protocols. ${ }^{41}$

\section{Eligibility criteria}

Study types

All RCTs of COH protocols in IVF/ICSI will be included. Non-randomised, cross-over design and quasi-randomised studies will be excluded.

\section{Participants}

The review will consider trials that include PORs undergoing $\mathrm{COH}$ during IVF/ICSI treatment. Ovarian stimulation protocols for IVF/ICSI will not be limited. POR women will be included regardless of age, patient's definition or expected response to the $\mathrm{COH}$ protocol.

\section{Types of interventions}

RCTs comparing one $\mathrm{COH}$ protocol to another will be included. Trials using Gns for ovulation induction that do not involve IVF/ICSI, studies using anti-oestrogens or aromatase inhibitors alone without Gns, and trials comparing different $\mathrm{Gn}$ doses in the same $\mathrm{COH}$ protocol, will be excluded. Gn preparations available for use include human menopausal Gn (hMG), a urinary product with FSH and luteinising hormone (LH) activity, purified FSH (p-FSH) and highly purified FSH (hp-FSH), and various recombinant FSH $(\mathrm{rFSH})$ and $\mathrm{LH}(\mathrm{rFSH} / \mathrm{rLH})$ preparations. From the relevant systematic reviews, at least 10 $\mathrm{COH}$ protocols for predicted PORs have been identified with multiple comparisons as depicted in the following network diagrams. If any other protocols are identified in the included studies, they will be considered as eligible and included in the NMA after assessing their comparability with those listed earlier. Table 1 lists the available $\mathrm{COH}$ protocols used in the network diagrams. An ideal network plot that is a fully connected network with all expected interventions has been generated (figure 1). 
Table 1 Available controlled ovarian hyperstimulation protocols used in the network diagrams

\begin{tabular}{|c|c|c|}
\hline COH protocol & Abbreviation & Description \\
\hline Long GnRH agonist & Long & $\begin{array}{l}\text { Down-regulation with } \mathrm{GnRH} \text { agonist } 0.1 \mathrm{mg} / \text { day is performed from day } 21 \text { of the } \\
\text { previous cycle. It is reduced to } 0.05 \mathrm{mg} / \mathrm{day} \text { from the start of the following cycle and } \\
\text { continued until hCG administration. Gn is started at day } 2-3 \text { of menses using a dose } \\
\text { of } 300 \mathrm{IU} \text { of rFSH. The Gn dose is adjusted from day } 6 \text { of stimulation according to } \\
\text { the ovarian response monitored until the day of hCG administration. }\end{array}$ \\
\hline Short GnRH agonist & Short & $\begin{array}{l}\text { GnRH-a administration is commenced at the same time as starting stimulation and } \\
\text { continued until the day of hCG administration. Women receive GnRH agonist } 0.05 \\
\text { mg/day starting on day } 1 \text { until the hCG injection and } 450 \mathrm{IU} \text { rFSH daily starting on } \\
\text { day } 2 \text {. }\end{array}$ \\
\hline
\end{tabular}

\begin{tabular}{|c|c|c|}
\hline Stop $\mathrm{GnRH}$ agonist & Stop & $\begin{array}{l}\text { Administration of } \mathrm{GnRH} \text { agonist } 0.1 \mathrm{mg} / \text { day starts in the mid-luteal phase in the } \\
\text { previous cycle and stops at the time of menstruation before starting } \mathrm{Gn} \text { stimulation } \\
\text { on day } 2 \text { of the menstrual cycle. Gn at } 300-450 \mathrm{IU} / \text { day is initiated, and careful } \\
\text { monitoring of follicular growth is performed using transvaginal ultrasound until >1 } \\
\text { follicle on both ovaries reaches a diameter of } 14 \mathrm{~mm} \text {, when GnRH antagonist is } \\
\text { injected subcutaneously until the date of hCG trigger. }\end{array}$ \\
\hline $\begin{array}{l}\text { Flare up } \mathrm{GnRH} \\
\text { agonist }\end{array}$ & Flare & $\begin{array}{l}\text { Administration of } \mathrm{GnRH}-\mathrm{a} 0.05 \mathrm{mg} / \mathrm{day} \text { starts from day } 2 \text { of the cycle. GnRH agonist } \\
\text { is administered subcutaneously and continued daily up to and including the day of } \\
\text { hCG administration. }\end{array}$ \\
\hline $\mathrm{GnRH}$ antagonist & $\mathrm{GnRH}-\mathrm{A}$ & $\begin{array}{l}\text { Gn is administered daily from menstrual cycle day } 3 \text {; follicle monitoring is performed } \\
5 \text { days later. When the dominant follicles reach a diameter of approximately } 14 \mathrm{~mm} \text {, } \\
\mathrm{GnRH} \text { antagonist } 0.125-0.25 \mathrm{mg} / \text { day is administered up to the trigger day. The dose } \\
\text { of } \mathrm{Gn} \text { can be adjusted according to ovarian response. }\end{array}$ \\
\hline $\begin{array}{l}\text { Delayed start } \mathrm{GnRH} \\
\text { antagonist }\end{array}$ & Delay & $\begin{array}{l}\text { Administration of } \mathrm{GnRH} \text { antagonist starts on day } 2 \text { or } 3 \text { of the menstrual cycle and } \\
\text { continues until the ninth day. Then, ovarian stimulation with } \mathrm{Gn} \text { is started from day } 9 \\
\text { of the menstrual cycle until the day of hCG administration. }\end{array}$ \\
\hline Natural cycle & Natural & $\begin{array}{l}\text { Starting on day } 8,1 \text { or } 12 \text { of their cycle, regular ultrasonic evaluation of the } \\
\text { endometrium thickness and mean diameter of the dominant follicle is performed. } \\
\text { When the endometrium thickness is }>8 \mathrm{~mm} \text { and the diameter of the dominant follicle } \\
\text { is } 16-20 \mathrm{~mm} \text {, ovulation is induced using hCG injection. }\end{array}$ \\
\hline $\begin{array}{l}\text { Luteal phase ovarian } \\
\text { stimulation }\end{array}$ & LPOS & $\begin{array}{l}\text { Between } 0 \text { and } 24 \text { hours after spontaneous ovulation or oocyte retrieval, patients } \\
\text { with at least one follicle measuring }<8 \mathrm{~mm} \text { are administered hMG injection until the } \\
\text { day of hCG administration. }\end{array}$ \\
\hline $\begin{array}{l}\text { Progestin-primed } \\
\text { ovarian stimulation }\end{array}$ & PPOS & $\begin{array}{l}\text { Administration of } \mathrm{hMG} \text { and MPA starts daily from cycle day } 3 \text {. Follicles are monitored } \\
5 \text { days later, and the dose of hMG is adjusted according to ovarian response. MPA } \\
\text { dose is consistent up to the trigger day. }\end{array}$ \\
\hline
\end{tabular}

$\mathrm{COH}$, controlled ovarian hyperstimulation; FSH, follicle-stimulating hormone; Gn, gonadotropin; GnRH, gonadotropin-releasing hormone; hCG, human chorionic gonadotropin; hMG, human menopausal gonadotropin; LPOS, Luteal phase ovarian stimulation; MPA, medroxyprogesterone acetate; PPOS, Progestin-primed ovarian stimulation; rFSH, recombinant follicle-stimulating hormone.

\section{Outcome measures}

Primary outcomes will include LBR (a baby born alive) and number of oocytes retrieved (NOR). Secondary outcomes will include clinical pregnancy rate (CPR, a gestational sac confirmed by ultrasound), ongoing pregnancy rate (OPR, a gestational sac with foetal heart motion, confirmed on ultrasound), miscarriage rate (MR, (CPR-OPR)/CPR), ovarian hyperstimulation syndrome (OHSS) rate (number of women experiencing OHSS events as defined by the trialists), multiple pregnancy rate (MPR, counted as one live birth event) and cycle cancellation rate $(\mathrm{CCR}$, defined as cancelled cycle before oocyte retrieval). The longest follow-up time will be chosen as the measurement time point for all of the outcomes.

\section{Data sources and search strategy}

A systematic search of the PubMed, Embase, Cochrane Library and Web of Science databases, as well as the Chinese databases SinoMed (formerly Chinese Biomedical Database), CNKI (Chinese National Knowledge Infrastructure), Wanfang Data and VIP Database for Chinese Technical Periodicals, from their inception to 31 March 2020, will be performed. Trial registers of ongoing and registered trials (clinicaltrials.gov) and OpenGrey (www. 


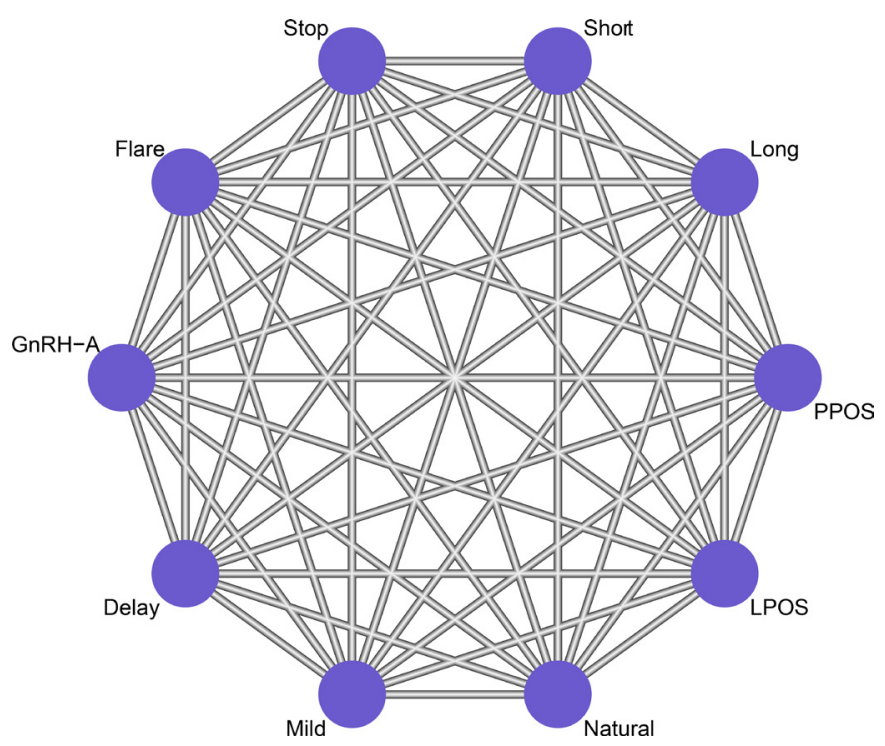

Figure 1 Network diagrams of possible comparisons of controlled ovarian hyperstimulation protocols for poor ovarian responder. Delay, delayed start; Flare, flare up $\mathrm{GnRH}$ agonist; $\mathrm{GnRH}-\mathrm{A}, \mathrm{GnRH}$ antagonist; Long, long $\mathrm{GnRH}$ agonist; Mild, mild ovarian stimulation; Natural, natural cycle; Short, short $\mathrm{GnRH}$ agonist; Stop, stop GnRH agonist; LPOS, Luteal phase ovarian stimulation; PPOS, Progestin-primed ovarian stimulation.

opengrey.eu) will be searched for unpublished literature. In addition, the proceedings of three major annual conferences on assisted reproduction technology will be searched: the American Society for Reproductive Medicine, the European Society for Human Reproduction and Embryology and the Pacific Coast Reproductive Society. The reference lists of published reviews and retrieved studies will be manually searched for additional trials. Search terms will be grouped into three blocks (table 2). The search strategy was developed and adapted for each database without language restrictions.

\section{Study selection process}

NoteExpress V.3.2 (Beijing Aegean Le Technology, Beijing, China) will be used to manage the citations retrieved from literature. After initial screening of titles and abstracts, the full text of all potentially eligible trials will be retrieved. Two authors (HY and CZ) will independently review these full-text articles for inclusion criteria and select the eligible RCTs. Disagreement between the reviewers will be resolved by discussion with the corresponding author (YF). For duplicate publications, more detailed and comprehensive literature that provides information and data will be retained. The reasons for study exclusion during this stage will be documented and reported, and the selection process will be illustrated in a Preferred Reporting Items for Systematic Reviews and Meta-Analyses flow chart.

\section{Data extraction}

Two independent reviewers (XTL and MZH) will screen the eligible studies and extract the data separately. Basic information extracted from the eligible studies will be entered into a standardised data extraction form and will include the following: author; year of publication; trial setting; country; singlecentre or multicentre study; total number of cases; number of patients; POR diagnosis; age; body mass index (BMI); duration of infertility; $\mathrm{COH}$ protocol; type of antagonist; type of agonist; type of $\mathrm{Gn}$; starting dose of $\mathrm{Gn}$; type and dose of trigger medication;

Table 2 Search terms

\begin{tabular}{l} 
Search block \\
\hline Participants
\end{tabular}

\section{Search terms}

Intervention "poor responders" OR "poor responder" OR "poor prognostic patients" OR "poor ovarian responder" OR "poor ovarian response" OR "inappropriate ovarian response" OR "diminished ovarian reserve" OR "low prognosis" OR "poor prognosis"

"IVF" OR "ICSI" OR "ET" OR "intracytoplasmic sperm injection techniques" OR "intracytoplasmic sperm injection" OR "in-vitro fertilisation" OR "in vitro fertilization" OR "Embryo Transfer" OR "ovarian stimulation" OR "controlled ovarian stimulation" OR "ovulation induction" OR "ovulation stimulation" OR "superovulation" OR "superovulation induction" OR "ovarian hyperstimulation" OR "controlled ovarian hyperstimulation" OR "controlled ovarian stimulation" OR "COH" OR "long agonist protocol" OR "long-long protocol" OR "long protocol" OR "Iong v short protocol" OR "short protocol" OR "stimulated cycle" OR "Stimulation techniques" OR "stop protocol" OR "flare-down" OR "flare-up" OR "flare-up GnRH agonist" OR "flare-up protocol" OR "micro-dose GnRH-a flare" OR "micro-dose HCG" OR "microdose flare cycle" OR "microdose flare-up protocol" OR "microdose GnRH agonist flare" OR "flexible protocol" OR "multidose antagonist protocol" OR "GnRH agonist short protocol" OR "GnRH agonist vs antagonist" OR "gonadotrophin stimulation" OR "mild ovarian stimulation" OR "mild protocol" OR "mild stimulated" OR "mild stimulation" OR "GnRH-a" OR "GnRH agonist" OR "GnRH agonists" OR "GnRH analog" OR "GnRH analogue" OR "GnRH analogues" OR "GnRH antagonist" OR "GnRH antagonists" OR "GnRHa" OR "GnRHa-gonadotropin" OR "Gonadorelin" OR "gonadotropin releasing hormone agonist" OR "Gonadotrophin releasing agonist" OR "natural cycle" OR "natural cycles" OR "modified natural cycle" OR "artificial cycle"

Study design ("randomized controlled trial" OR "controlled clinical trial" OR "randomized" OR "placebo" OR "clinical trials as topic" OR "randomly") NOT ("animals" NOT "humans") 
outcome data; randomisation method; allocation concealment; power calculation and financial support. The literature will be arranged in accordance with the code of intervening measures. The extracted data will be entered into a standardised spreadsheet file (Excel). If details of the included studies are inadequate to enable accurate grouping, the authors of the studies will be contacted for more detail.

\section{Evaluation of risk of bias}

Risk of bias will be assessed as 'low risk', 'some concerns risk' or 'high risk', in accordance with V.2 of the Cochrane Risk-of-Bias Tool for Randomized Trials (RoB 2) in the Cochrane Handbook for Systematic Reviews of Interventions (V.6, 2019). ${ }^{42}$ This tool includes domains of bias: randomisation process, deviations from intended interventions, missing outcome data, measurement of the outcome selection of the reported result and overall risk. Two authors (HX and QZ) will independently assess the risk of bias in the selected studies, and inconsistencies in evaluation will be resolved by another author (YF).

\section{Data synthesis}

For dichotomous data, results will be expressed as a summary risk ratio (RR) with corresponding 95\% CIs. Continuous data will be expressed as standardised mean difference with corresponding $95 \%$ CI.

\section{Pairwise meta-analysis for direct treatment comparisons}

Traditional pairwise meta-analyses will be performed for all available direct evidence comparing two treatments using the bayesmeta package (V.2.5-0) in R (V.4.0.1). Bayesian random-effects meta-analysis will be used for data analysis.

\section{NMA for indirect and mixed comparisons}

The NMA will be conducted in a Bayesian hierarchical framework using the Markov Chain Monte Carlo (MCMC) framework and fitted the gemtc package (V.0.8-2) and the BUGSnet package (V.1.0.3) in R (V.4.0.1). ${ }^{43}$ Deviance information criterion (DIC) statistics and leverage plots will be used to assess random effect model fit and to ensure that the overall fit is adequate. ${ }^{44}$ Three chains with different initial values will be run simultaneously. For each analysis, the inference will be based on 150000 iterations of MCMC after a 50000 iteration burn-in period. Trace plots and Brooks-Gelman-Rubin diagnostic plots will be used to assess convergence. ${ }^{45}$

Clinical and methodological heterogeneity will be assessed by examining the characteristics and design of the studies included. The transitivity assumption underlying the NMA will be evaluated by comparing the distribution of clinical and methodological variables which could act as effect modifiers across treatment comparisons. The common $\mathrm{COH}$ protocol that is used to compare different protocols indirectly is similar when it appears in different comparisons (eg, long $\mathrm{GnRH}$ agonist protocol vs short GnRH agonist protocol is similar to long GnRH agonist protocol vs 'flare up' GnRH agonist protocol).
Plots displaying clinical characteristics within each $\mathrm{COH}$ protocol arm will be generated. The statistical heterogeneity of entire NMA will be investigated using the magnitude of heterogeneity variance $\left(\tau^{2}\right)$ estimated from the NMA model. The estimate of the heterogeneity variance in the NMA will be compared with the estimates in the pairwise meta-analyses. Statistical evaluation of inconsistency will be conducted by separating direct evidence from indirect evidence on a specific comparison.

For each outcome, the treatment ranking will be summarised and reported as the surface under the cumulative ranking curve. Each iteration of the Markov chain produces a ranking of the treatments, from most effective to least effective. The percentages obtained by accumulating that information provide estimates of the probability of each treatment being in each position in the ranking, equal to $100 \%$ when the treatment is certain to be the best and 0 when it is certain to be the worst. ${ }^{40}$ Comparison-adjusted funnel plots will be performed to investigate whether the integrated results have a difference between imprecise and precise trials.

\section{Subgroup analysis and network meta-regression}

If important heterogeneity and/or inconsistency is found, possible sources will be explored. If sufficient studies are available, network meta-regression or subgroup analyses will be performed using the following effect modifiers as possible sources of inconsistency and or heterogeneity: age; BMI; POR diagnosis (Bologna's criteria vs no Bologna's criteria); country (Asia or not Asia); baseline FSH level; baseline AMH level; baseline AFC level; the dosage of $\mathrm{Gn}$; regimen; route of drug administration and mixed $\mathrm{rFSH}$ or $\mathrm{hMG} / \mathrm{rLH}$ versus standard protocols $(\mathrm{rFSH}$ or hMG).

\section{Sensitivity analysis}

To assess the robustness of the results obtained by the primary model, sensitivity analyses for the following will be performed: overall quality of the studies (low vs high risk of overall bias); use of fixed-effect versus randomeffects model and different effect measures (RR vs OR); different definition and calculation of pregnancy-related outcomes.

The list of detailed data analysis reports, we will submit to a peer-reviewed journal is provided in online supplemental file 1 .

\section{Dealing with the missing data}

In cases of missing data, the authors will be contacted for the original data. If the original data cannot be obtained, missing data will be calculated using the outcome indicators provided in the article, such as using CPR and OPR to calculate MR. If there is high-level missing data $(>15 \%$ of missing data), the authors will use multiple imputation to estimate missing data. Furthermore, sensitivity analysis will be used to explore the impact of high-level missing data on the results of the overall estimation of treatment effect. 


\section{Assessment of confidence in network estimates}

A 'summary of findings table' will be produced using CINeMA (Confidence in Network Meta-Analysis), which is a web application (see https://cinema.ispm.unibe. $\mathrm{ch} /$ ) that simplifies the evaluation of confidence in the findings from NMA. ${ }^{46}$ This table will evaluate the overall quality of the body of evidence for the primary outcomes (LBR and OR) on the basis of within-study bias, indirectness, imprecision, heterogeneity and inconsistency, and reporting bias. The quality of evidence will be classified according to the Grading of Recommendations, Assessment, Development and Evaluations group into four levels: high, moderate, low and very low quality.

\section{Ethics and dissemination}

This review does not require ethics approval because it does not require the collection of primary data. Findings of the NMA will be published in a peer-reviewed journal for dissemination.

\section{Patient and public involvement}

There was no patient or public involvement in the design of this study, or the development and drafting of this manuscript.

\section{DISCUSSION}

This systematic review and Bayesian NMA will compare current $\mathrm{COH}$ protocols in women who are POR undergoing IVF/ICSI, and generate a clinically useful ranking of these regimens. The results of this NMA will make it easier for POR patients undergoing IVF/ICSI and their physicians to choose the appropriate $\mathrm{COH}$ strategy. However, the interpretation based on evidence from the NMA for ranking results is limited. As such, it needs to be combined with clinical experience and the specific situations of patients with POR. Previous published systematic reviews and meta-analyses only included RCTs before 2018. Importantly, some published RCTs and trials have provided additional data regarding $\mathrm{COH}$ for IVF/ ICSI. ${ }^{47-49}$ Additionally, the natural cycle and progestinprimed ovarian stimulation were not considered in previous studies. To our knowledge, this will be the first NMA aimed at determining the optimal $\mathrm{COH}$ protocol for POR women during IVF/ICSI treatment. Our findings will contribute to the development of clinical practice guidelines for $\mathrm{COH}$ protocols to improve the pregnancy and the NOR of IVF/ICSI. Nevertheless, our NMA may have limitations. First, the different diagnostic criteria and the various $\mathrm{Gn}$ preparations (ie, rFSH, HMG, rLH, uMG and $\mathrm{rFSH} / \mathrm{rLH}$ ) may cause potential heterogeneity. Second, differences in the definition and calculation of pregnancy-related outcomes may affect the quality of evidence.

\section{Author affiliations}

${ }^{1}$ Institute of Acupuncture and Moxibustion, China Academy of Chinese Medical Sciences, Beijing, China
${ }^{2}$ Reproductive medicine center, Shenzhen Maternity \& Child Healthcare Hospital, Shenzhen, China

${ }^{3}$ Department of Endocrinology Nephropathy, Dongzhimen Hospital Affiliated to Beijing University of Chinese Medicine, Beijing, China

${ }^{4}$ Institute of Basic Research in Clinical Medicine, China Academy of Chinese Medical Sciences, Beijing, China

Acknowledgements We thank the support of the National Key Research and Development Programme of TCM Modernization Research Project and the National Natural Science Foundation of China.

Contributors HY and YF conceived the network meta-analysis. XL, MH and HX participated in the literature quality assessment, data extraction and analysis. $\mathrm{CZ}$ and QZ explained the results. HY and YF drafted the agreement. CZ revised this manuscript. All authors reviewed the protocol and approved the submission of the final manuscript.

Funding This work is supported by the National Key Research and Development Programme of TCM Modernization Research Project (grant no. 2017YFC1703603), and the National Natural Science Foundation of China (grant no. 81674087).

Competing interests None declared.

Patient consent for publication Not required.

Provenance and peer review Not commissioned; externally peer reviewed.

Supplemental material This content has been supplied by the author(s). It has not been vetted by BMJ Publishing Group Limited (BMJ) and may not have been peer-reviewed. Any opinions or recommendations discussed are solely those of the author(s) and are not endorsed by BMJ. BMJ disclaims all liability and responsibility arising from any reliance placed on the content. Where the content includes any translated material, BMJ does not warrant the accuracy and reliability of the translations (including but not limited to local regulations, clinical guidelines, terminology, drug names and drug dosages), and is not responsible for any error and/or omissions arising from translation and adaptation or otherwise.

Open access This is an open access article distributed in accordance with the Creative Commons Attribution Non Commercial (CC BY-NC 4.0) license, which permits others to distribute, remix, adapt, build upon this work non-commercially, and license their derivative works on different terms, provided the original work is properly cited, appropriate credit is given, any changes made indicated, and the use is non-commercial. See: http://creativecommons.org/licenses/by-nc/4.0/.

\section{ORCID iDs}

Huisheng Yang http://orcid.org/0000-0001-8897-953X

Qiyan Zheng http://orcid.org/0000-0001-9276-3766

Mingzhao Hao http://orcid.org/0000-0002-0767-2112

\section{REFERENCES}

1 MurrayCJL, CallenderCSKH, KulikoffXR, et al. Population and fertility by age and sex for 195 countries and territories, 1950-2017: a systematic analysis for the global burden of disease study 2017. Lancet 2018;392:1995-2051.

2 Mascarenhas MN, Flaxman SR, Boerma T, et al. National, regional, and global trends in infertility prevalence since 1990: a systematic analysis of 277 health surveys. PLoS Med 2012;9:e1001356.

3 , Calhaz-Jorge $C$, et al, European IVF-monitoring Consortium (EIM), European Society of Human Reproduction and Embryology (ESHRE). Assisted reproductive technology in Europe, 2013: results generated from European registers by ESHRE. Hum Reprod 2017;32:1957-73.

4 Ferraretti AP, La Marca A, Fauser BCJM, et al. ESHRE consensus on the definition of 'poor response' to ovarian stimulation for in vitro fertilization: the Bologna criteria. Hum Reprod 2011;26:1616-24.

5 Xu B, Chen Y, Geerts D, et al. Cumulative live birth rates in more than 3,000 patients with poor ovarian response: a 15-year survey of final in vitro fertilization outcome. Fertil Steril 2018;109:1051-9.

6 Jamaludin R, Ahmad MF, Park D-K, et al. The stimulation protocol in poor responder IVF; a minimal or high-dose stimulation? - A meta-analysis. Horm Mol Biol Clin Investig 2019;41. doi:10.1515/ hmbci-2019-0018. [Epub ahead of print: 29 Nov 2019].

7 Zhang Y, Zhang C, Shu J, et al. Adjuvant treatment strategies in ovarian stimulation for poor responders undergoing IVF: a systematic review and network meta-analysis. Hum Reprod Update 2020;26:247-63.

8 Farquhar C, Rishworth JR, Brown J, et al. Assisted reproductive technology: an overview of Cochrane reviews. Cochrane Database Syst Rev 2015;2015:CD010537. 
9 Farquhar C, Marjoribanks J. Assisted reproductive technology: an overview of Cochrane reviews. Cochrane Database Syst Rev 2018;8:CD010537.

10 Grisendi V, Mastellari E, La Marca A. Ovarian reserve markers to identify poor responders in the context of poseidon classification. Front Endocrinol 2019;10:218.

11 Vaiarelli $\mathrm{A}$, Cimadomo D, Ubaldi $\mathrm{N}$, et al. What is new in the management of poor ovarian response in IVF? Curr Opin Obstet Gynecol 2018;30:1-62.

12 Roman R, Mussarat N, Detti L. Ovarian stimulation in poor responders: have we made progress? Curr Pharm Biotechnol 2017;18:614-8.

13 Özkan ZS. Ovarian stimulation modalities in poor responders. Turk $J$ Med Sci 2019;49:959-62.

14 Cozzolino M, Franasiak J, Andrisani A, et al. "Delayed start" gonadotropin-releasing hormone antagonist protocol in Bologna poor-responders: A systematic review and meta-analysis of randomized controlled trials. Eur J Obstet Gynecol Reprod Biol 2020;244:154-62.

15 Schimberni M, Ciardo F, Schimberni M, et al. Short gonadotropinreleasing hormone agonist versus flexible antagonist versus clomiphene citrate regimens in poor responders undergoing in vitro fertilization: a randomized controlled trial. Eur Rev Med Pharmacol Sci 2016;20:4354-61.

16 Liu X, Li T, Wang B, et al. Mild stimulation protocol vs conventional controlled ovarian stimulation protocol in poor ovarian response patients: a prospective randomized controlled trial. Arch Gynecol Obstet 2020;301:1331-9.

17 Prapas Y, Petousis S, Dagklis T, et al. GnRH antagonist versus long $\mathrm{GnRH}$ agonist protocol in poor IVF responders: a randomized clinical trial. Eur J Obstet Gynecol Reprod Biol 2013;166:43-6.

18 Morgia F, Sbracia M, Schimberni M, et al. A controlled trial of natural cycle versus microdose gonadotropin-releasing hormone analog flare cycles in poor responders undergoing in vitro fertilization. Fertil Steril 2004;81:1542-7.

19 Lambalk CB, Banga FR, Huirne JA, et al. GnRH antagonist versus long agonist protocols in IVF: a systematic review and meta-analysis accounting for patient type. Hum Reprod Update 2017;23:560-79.

20 Xiao J, Chang S, Chen S. The effectiveness of gonadotropinreleasing hormone antagonist in poor ovarian responders undergoing in vitro fertilization: a systematic review and meta-analysis. Fertil Steril 2013:100:1594-601.

21 Nabati A, Peivandi S, Khalilian A, et al. Comparison of GnRh agonist Microdose flare up and GnRh Antagonist/Letrozole in treatment of poor Responder patients in intra Cytoplaspic sperm injection: randomized clinical trial. Glob J Health Sci 2015;8:166-71.

22 Davar R, Rahsepar M, Rahmani E. A comparative study of luteal estradiol pre-treatment in $\mathrm{GnRH}$ antagonist protocols and in micro dose flare protocols for poor-responding patients. Arch Gynecol Obstet 2013;287:149-53.

23 Chen Q, Chai W, Wang Y, et al. Progestin vs. gonadotropin-releasing hormone antagonist for the prevention of premature luteinizing hormone surges in poor responders undergoing in vitro fertilization treatment: a randomized controlled trial. Front Endocrinol 2019;10.

24 Fan $\mathrm{Y}$, Zhang X, Hao Z, et al. Effectiveness of mild ovarian stimulation versus $\mathrm{GnRH}$ agonist protocol in women undergoing assisted reproductive technology: a meta-analysis. Gynecol Endocrinol 2017:33:746-56.

25 Song D, Shi Y, Zhong Y, et al. Efficiency of mild ovarian stimulation with clomiphene on poor ovarian responders during IVFVICSI procedures: a meta-analysis. Eur J Obstet Gynecol Reprod Biol 2016;204:36-43.

26 Youssef MA-F, van Wely M, Mochtar M, et al. Low dosing of gonadotropins in in vitro fertilization cycles for women with poor ovarian reserve: systematic review and meta-analysis. Fertil Steril 2018;109:289-301.

27 Al-Inany HG, Youssef MA, Ayeleke RO, et al. GonadotrophinReleasing hormone antagonists for assisted reproductive technology. Cochrane Database Syst Rev 2016;2016:CD001750.

28 Siristatidis CS, Gibreel A, Basios G, et al. Gonadotrophin-Releasing hormone agonist protocols for pituitary suppression in assisted reproduction. Cochrane Database Syst Rev 2015:CD006919.

29 Figueiredo JBP, Nastri CO, Vieira ADD, et al. Clomiphene combined with gonadotropins and $\mathrm{GnRH}$ antagonist versus conventional controlled ovarian hyperstimulation without clomiphene in women undergoing assisted reproductive techniques: systematic review and meta-analysis. Arch Gynecol Obstet 2013;287:779-90.

30 Gibreel A, Maheshwari A, Bhattacharya S. Clomiphene citrate in combination with gonadotropins for controlled ovarian stimulation in women undergoing in vitro fertilization. Cochrane Database Syst Rev 2012;11:CD008528.

31 Pu D, Wu J, Liu J. Comparisons of GnRH antagonist versus GnRH agonist protocol in poor ovarian responders undergoing IVF. Hum Reprod 2011;26:2742-9.

32 Kyrou D, Kolibianakis EM, Venetis CA, et al. How to improve the probability of pregnancy in poor responders undergoing in vitro fertilization: a systematic review and meta-analysis. Fertil Steril 2009:91:749-66.

33 Mochtar MH, Van Derder Veen F, Ziech M, et al. Recombinant luteinizing hormone $(\mathrm{rLH})$ for controlled ovarian hyperstimulation in assisted reproductive cycles. Cochrane Database Syst Rev 2007:CD005070.

34 Franco JG, Baruffi RLR, Mauri AL, et al. GnRH agonist versus GnRH antagonist in poor ovarian responders: a meta-analysis. Reprod Biomed Online 2006;13:618-27.

35 Griesinger G, Diedrich K, Tarlatzis BC, et al. GnRH-antagonists in ovarian stimulation for IVF in patients with poor response to gonadotrophins, polycystic ovary syndrome, and risk of ovarian hyperstimulation: a meta-analysis. Reprod Biomed Online 2006;13:628-38.

36 Kolibianakis EM, Collins J, Tarlatzis BC, et al. Among patients treated for IVF with gonadotrophins and $\mathrm{GnRH}$ analogues, is the probability of live birth dependent on the type of analogue used? A systematic review and meta-analysis. Hum Reprod Update 2006;12:651-71.

37 Ludwig M, Katalinic A, Diedrich K. Use of GnRH antagonists in ovarian stimulation for assisted reproductive technologies compared to the long protocol. meta-analysis. Arch Gynecol Obstet 2001;265:175-82.

38 Cipriani A, Higgins JPT, Geddes JR, et al. Conceptual and technical challenges in network meta-analysis. Ann Intern Med 2013;159:130-7.

39 Caldwell DM, Ades AE, Higgins JPT. Simultaneous comparison of multiple treatments: combining direct and indirect evidence. $B M J$ 2005;331:897-900

40 Riley RD, Jackson D, Salanti G, et al. Multivariate and network metaanalysis of multiple outcomes and multiple treatments: rationale, concepts, and examples. BMJ 2017;358:j3932.

41 Shamseer L, Moher D, Clarke M, et al. Preferred reporting items for systematic review and meta-analysis protocols (PRISMA-P) 2015: elaboration and explanation. BMJ 2015;350:g7647.

42 Higgins JPT, Savović J, Page MJ. Chapter 8: Assessing risk of bias in a randomized trial. In: Higgins JPT, Thomas J, Chandler J, eds. Cochrane Handbook for systematic reviews ofInterventions. 2nd Edition. Chichester, UK: John Wiley \& Sons, 2019: 205-28.

43 Béliveau A, Boyne DJ, Slater J, et al. BUGSnet: an R package to facilitate the conduct and reporting of Bayesian network metaanalyses. BMC Med Res Methodol 2019;19:196.

44 Dias S. Network meta-analysis for decision-making. Chichester, UK: John Wiley \& Sons, 2018: 69-70.

45 Dias S, Sutton AJ, Ades AE, et al. Evidence synthesis for decision making 2: a generalized linear modeling framework for pairwise and network meta-analysis of randomized controlled trials. Med Decis Making 2013;33:607-17.

46 Nikolakopoulou A, Higgins JPT, Papakonstantinou T, et al. CINeMA: an approach for assessing confidence in the results of a network meta-analysis. PLoS Med 2020;17:e1003082.

47 Moini A, Lavasani Z, Kashani L, et al. Letrozole as co-treatment agent in ovarian stimulation antagonist protocol in poor responders: a double-blind randomized clinical trial. Int J Reprod Biomed 2019;17:653-60.

48 Chen Q, Chai W, Wang Y, et al. Progestin vs. GonadotropinReleasing Hormone Antagonist for the Prevention of Premature Luteinizing Hormone Surges in Poor Responders Undergoing in vitro Fertilization Treatment: A Randomized Controlled Trial. Front Endocrinol 2019;10:796.

49 Norman RJ, Alvino H, Hull LM, et al. Human growth hormone for poor responders: a randomized placebo-controlled trial provides no evidence for improved live birth rate. Reprod Biomed Online 2019;38:908-15. 